\title{
CURRENCY HEDGING WITH HELP OF DERIVATIVES
}

\author{
S. Riederová \\ Received: December 17, 2010
}

\begin{abstract}
RIEDEROVÁ, S.: Currency hedging with help of derivatives. Acta univ. agric. et silvic. Mendel. Brun., 2011, LIX, No. 4, pp. 273-280

The high volatility combined with unpredictable fluctuations of CZK had shown one more time to the Czech exporting companies the necessity of currency hedging.

This article is focused on finding of suitable currency hedging instrument for exporting company, working with the currency pair of CZK/EUR.

In the first part, the time series analysis is made for volatility, interest rates and exchange rate. Based on the real market data - gained from Thomson REUTERS and CNB for the time period starting in 2002 - the detailed analysis is made in graphical form. The main goal is to find out the future trends with help of liner regression analysis, based on the historical data. Several graphs are provided with the trend line end estimated interval (min and max) for the each variable. The calculated values are clearly marked, to be separated from the real market data. Exchange rate curve shows the market behaviour in the last years and is to be used as most important indicator for the future trends. Interest rates curves are very important for the calculation of the BIPS (basis points), determining the price of the forwards. The difference between landing and deposit rates for the same period of time and different currencies are showing the market estimation of the future development of each currency. Forward price is to be seen as a benchmark for the all other financial instruments. And finally the volatility (quoted as middle) is very important part in the pricing of currency options.

The second part is closely connected with the first one. Based on the results of provided analyses, it recommends a suitable hedging product for the next period of time. All of the analyses are taken as an input in different ways. The volatility is important for the decision of selling or purchasing the specific part of currency option. The exchange rate outlook together with the interest rates is the indicator of the future development of the currency pair and is playing the most important role in the decision process regarding the kind of hedging.
\end{abstract}

volatility, currency, interest rates, EUR/CZK, hedging instruments, hedging strategy

The high volatility combined with unpredictable fluctuations of CZK had shown one more time to the Czech exporting companies the necessity of currency hedging.

Of course, there is a big difference between the hedging necessity of the exporting and importing company, but the main idea remain unchanged reducing the currency risk.

The understanding of currency risk and its management by corporations has come a long way in the past. One of the main impulses for corporate executives to pay attention on this risk was the break-up of Bretton Woods (HENDERSON, C., 2002). The new situation, where the currencies have been allowed to fluctuate in the wide range, changed the attitude of executives. Since them, the currency risk becomes to be an important issue and a part of the corporate risk management strategy. The development in this area was very turbulent in last twenty years. As expected, the big corporate started with simple hedging instruments like forwards and swaps. After collecting some experience, they have realised, the simple hedging will not work in every business and on each market. This was the 
point where the currency options have been really introduced (at first only the plain vanilla, later on the more sophisticated structures) and a new industry - financial engineering - was established. To understand this entire new product, the corporate reacts with hiring of real professionals, able to manage the daily operations in risk management (HENDERSON, C., 2002).

Unmanaged currency risk may have a big impact on corporate cash flow, operating profit as well as asset and liabilities valuation. Managing of this risk makes the corporate results more predictable. After acceptance of the managing - premise, the corporate has according to HENDERSON (2002) set up three points:

1. Define a field, where the net exposure exists

- Transaction risk (claims, receivables, etc.)

- Translation risk (balance sheet)

- Economic risk (present value of future operating cash flow).

2. Define a corporate Treasury strategy to deal with these currency risks.

3. Define the proper financial instruments for hedging.

This paper is focused on finding the proper currency hedging instrument for exporting company, working with the currency pair of CZK/EUR.

In the first part, the time series analysis is made for volatility, interest rates and exchange rate. Based on the real market data the detailed analysis is made in the graphical form. The main goal is to find out the future trends with help of linear regression analysis, based on the historical data. Several graphs are provided with the trend line end estimated interval (min and $\max$ ) for the each variable. The calculated values are clearly marked, to be separated from the real market data. Exchange rate curve shows the market behaviour in the last years and is to be used as most important indicator for the future trends. Interest rates curves are very important for the calculation of the BIPS (basis points), determining the price of the forwards (CHISHOLM, A. M., 2010). The difference between EUR and CZK deposit rates for the same period of time and different currencies are showing the market estimation of the future development of each currency. Forward price is to be seen as a benchmark for the all other financial instruments. And finally the volatility (quoted as middle) is very important part in the pricing of currency options.

The second part is closely connected with the first one. Based on the results of provided analyses, it recommends a range of suitable hedging products for the next period of time. All of the analyses are taken as an input in different ways. The volatility is important for the decision of selling or purchasing the specific part of currency option. The exchange rate outlook together with the interest rates is the indicator of the future development of the currency pair and is playing the most important role in the decision process regarding the kind of hedging.

\section{METHODS AND RESOURCES}

Linear regression with least squares estimation will be used for the time series analysis of exchange rates and volatilities. Regression analysis is the statistical method for investigating of causal relationship between two or more variables. This method is based on Gauss-Markov theorem, referring the usage of least squares method in the area of the general linear models. This model is a special case of statistical model, which is a simple description of a state or process. This kind of model can't be verified by an experiment or with some other external help (YAN, X., GANG SU, X., 2009).

There are three basic types of regression. Two of them are liner, the last one is non-linear.

1. Simple linear regression, which is for modelling the linear relationship between two variables. This regression model is mostly written as following form (YAN, X., GANG SU, X., 2009):

$$
y=\beta_{0}+\beta_{1} x+\varepsilon,
$$

where $\beta_{0}$ and $\beta_{1}$ are referred to as a parameters of the model ( $\beta_{1}$ is gradient), $y$ is the dependent variable, $x$ is independent variable, and $\varepsilon$ is the error term. The normal distribution is usually assumed for the error $\varepsilon$ with $\mathrm{E}_{(\varepsilon)}=0$ and a constant variance $\operatorname{Var}_{(\varepsilon)}=\sigma^{2}$ (YAN, X., GANG SU, X., 2009). Based on ANDERSON (2007) the regression equation for expected $y$, denoted $E(y)$ can be written as follows:

$$
E(y)=\beta_{0}+\beta_{1} x,
$$

where the graphical representation will be a straight line.

2. Multiple linear regression model is characterized with one dependent variable and more than one independent variables. The basic assumption is, that the response variable is a linear function of the model parameters and there are more than one independent variables in the model. The multiple linear regression model takes following form (YAN, X., GANG SU, X., 2009):

$$
y=\beta_{0}+\beta_{1} x_{1}+\ldots+\beta_{p} x_{p}+\varepsilon,
$$

where $y$ is the dependent variable, $\beta_{0}, \beta_{1}, \beta_{2} \ldots \beta_{p}$ are parameters (= regression coefficients), and $x_{p}$, $x_{2} \ldots x_{n}$ are independent variables in the model. The same assumption is used for the error term $\varepsilon$, $\mathrm{E}_{(\varepsilon)}=0$ and $\operatorname{Var}_{(\varepsilon)}=\sigma^{2}$ (YAN, X., GANG SU, X., 2009). Mathematical description of the relation between the mean value of $\mathrm{y}$ and multiple $\mathrm{x}$, known as multiple regression equation (ANDERSON D. R., 2007) can be written as:

$$
E(y)=\beta_{0}+\beta_{1} x_{1}+\ldots+\beta_{p} x_{p} .
$$

3. Nonlinear regression assumes nonlinear relationship between dependent and independent variables. Example growth model (one of the nonlinear models) may be written as (YAN, X., GANG SU, X., 2009): 


$$
y=\frac{\alpha}{1+e^{\beta t}}+\varepsilon
$$

where $y$ - the growth is a function of time $t$, and $\beta$ are model parameters, and $\varepsilon$ is the random error. Similar to the am cases, the regression equation can be written as:

$$
E(y)=\frac{\alpha}{1+e^{\beta t}}
$$

with strong nonlinear characteristics (ANDERSON, D. R., 2007).

In accordance with YAN, X., GANG SU, X., (2009) there are three main purposes of regression analysis:

1. Causality - finding a relationship between $y$ and regressors $x_{1}, x_{2} \ldots x_{n}$

2. Predictability of $y$ based on a set of values of $x_{1}$, $x_{2} \ldots x_{n}$

3. Accuracy - identification of more important $x_{i}$, which can impact the $y$ in a stronger way than others. This method increase accuracy and works more efficient.

The least squares method for the simple linear regression model is a procedure for using sample data (or set of) to find the estimated regression equation. In this kind of model, the equation can be written as (ANDERSON, D. R., 2007):

$$
\hat{y}_{\mathrm{i}}=\beta_{0}+\beta_{1} x_{\mathrm{i}} .
$$

Based on this equation, the estimates $b_{0}, b_{1}$ are to be find, matching following criteria (YAN, X., GANG SU, X., 2009)

$$
\left(b_{0}, b_{1}\right)=\arg \min \sum_{i=1}^{n}\left[y_{i}+\left(\beta_{0}+\beta_{i} x_{i}\right)\right]^{2} .
$$

The graphical representation of this equation is nothing else as a straight line, going in the closest way of all data points. It can be mathematically transformed to the solving of following partial derivation system (WEISBERG, S., 2005):

$$
\begin{gathered}
\frac{\partial}{\partial \beta_{0}} \sum_{i=1}^{n}\left[y_{i}-\left(\beta_{0}+\beta_{i} x_{i}\right)\right]^{2}=0 \\
\frac{\partial}{\partial \beta_{1}} \sum_{i=1}^{n}\left[y_{i}-\left(\beta_{0}+\beta_{i} x_{i}\right)\right]^{2}=0 .
\end{gathered}
$$

Regarding the data, used for all the time series analysis and linear regression post processing, the market data from Thomson Reuters and CNB (Czech National Bank) has been used. From the

\begin{tabular}{|c|c|c|c|}
\hline Instrument & Definition & Advantages & Disadvantages \\
\hline Plain vanilla call & $\begin{array}{l}\text { Buy an upside strike in an exchange } \\
\text { rate with no obligations to exercise }\end{array}$ & $\begin{array}{l}\text { Simplicity, cheaper than FWD. } \\
\text { Max loss is the premium }\end{array}$ & $\begin{array}{l}\text { Higher cost than more } \\
\text { sophisticated structures }\end{array}$ \\
\hline Call spread & Buy ATMF and sell a low delta call & Lower cost than a vanilla call & $\begin{array}{l}\text { Cover only for modest } \\
\text { movements }\end{array}$ \\
\hline "Seagull" & $\begin{array}{l}\text { Buy ATMF call, sell a low delta call } \\
\text { and downside put }\end{array}$ & $\begin{array}{l}\text { Can be structured to be zero } \\
\text { cost }\end{array}$ & $\begin{array}{l}\text { Not covered against major } \\
\text { spot move }\end{array}$ \\
\hline
\end{tabular}
data-set starting 1. 1. 2000 until 26. 10. 2010 has been chosen for this paper the time period from 1. 1.2002 until 26. 10. 2010.

\section{Traditional hedging structures}

I: Samples of traditional hedging structures

Source: HENDERSON, C., 2002, page 148-149

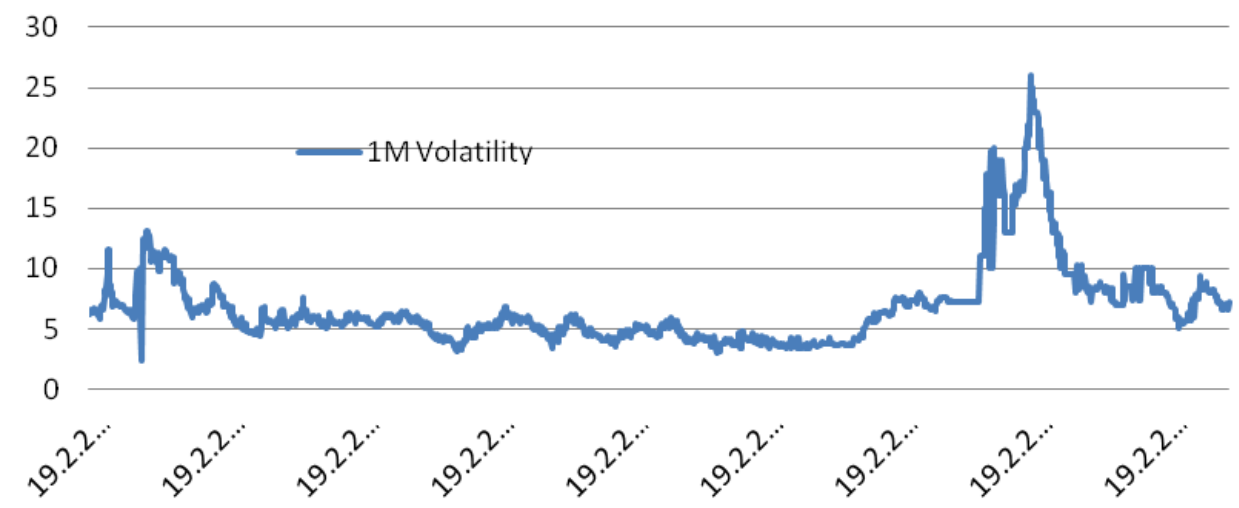

Source: Own graph based on Thomson Reuters (data provided by Komerční banka, a. s.)

1: 1 M Volatility for the time period 1. 1.2002-10.8.2010 


\section{RESULTS}

\section{Volatility}

The implied volatility is a theoretical parameter $\sigma$, which will in Black-Scholes formula return the current market price of an option (BOSSU, S., HENROTTE, P., 2006). From mathematical point of view:

$$
\mathrm{C}=\mathrm{f}(\sigma, \ldots),
$$

where $C$ is the theoretical value of calculated option, and $f$ is a specific pricing model depending on $\sigma$, along with others (HUNT, P., J., KENNEDY, J., E., 2000).

The graph in Fig.l shows the 1 month volatility, as traded in the specified period of time. The peak in second half of 2008 and beginning of 2009 reflects the start and duration of financial crisis. Such a singularity does not allow applying the linear regression, because of nonlinearity of statistical model.
Nevertheless, it is possible to adapt the model for the linear on with changing of the time period (Fig. 2).

Trading data from the year 2010 are not only upto-date, but they allow the usage of linear regression (the curve LR, Fig. 2). The result of linear regression for the year 2010 shows the clear decreasing trend for $1 \mathrm{M}$ volatility. The question is, if this trend remains for the future as well. In answer, there can be used the predictive function of linear regression to confirm or to disprove this hypothesis. Knowing the limitations by selecting the right model, three scenarios will be used for predicting (Fig. 3).

\section{- Scenario LR}

This scenario is based on a data model from 1.1 . 2009 until 10. 8. 2010 (historical data) and predicts the next month. Unfortunately, the first quarter of 2009 (with positive slope) and second quarter of the same year (strong negative slope) are characteristic with a high value of a standard deviation in LR computing. It means the first half of 2009 will affect significantly the whole LR curve. Therefore is the result - flat curve - not really significant for the volatility behaviour.

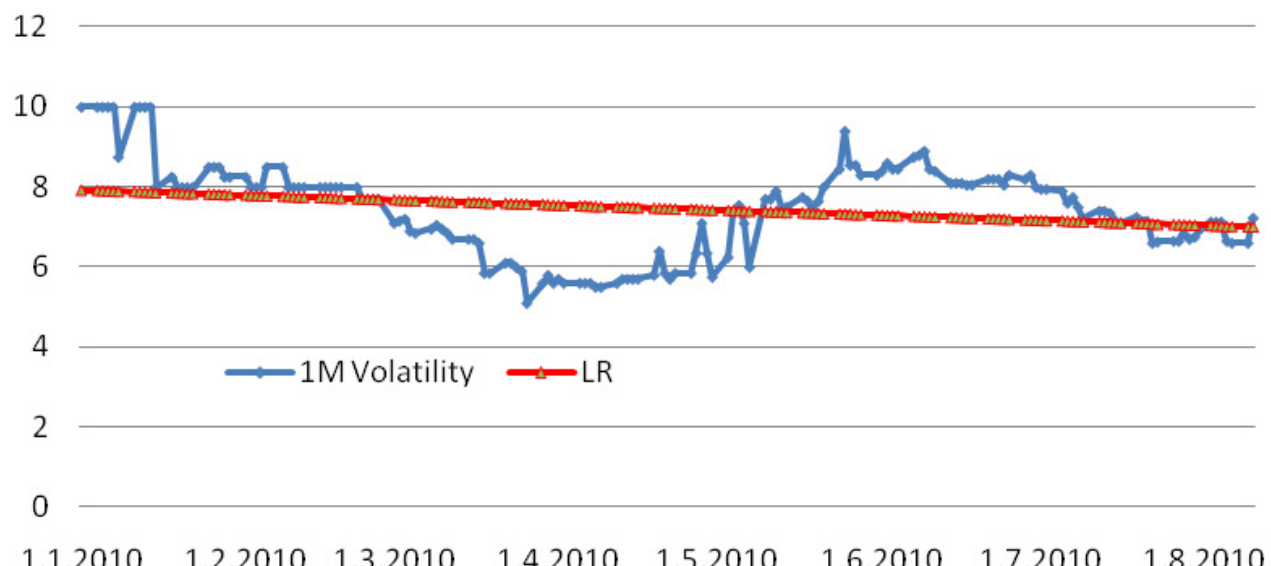

Source: Own calculations based on Thomson Reuters data

2: $1 M$ Volatility for the time period 2010 with linear regression curve

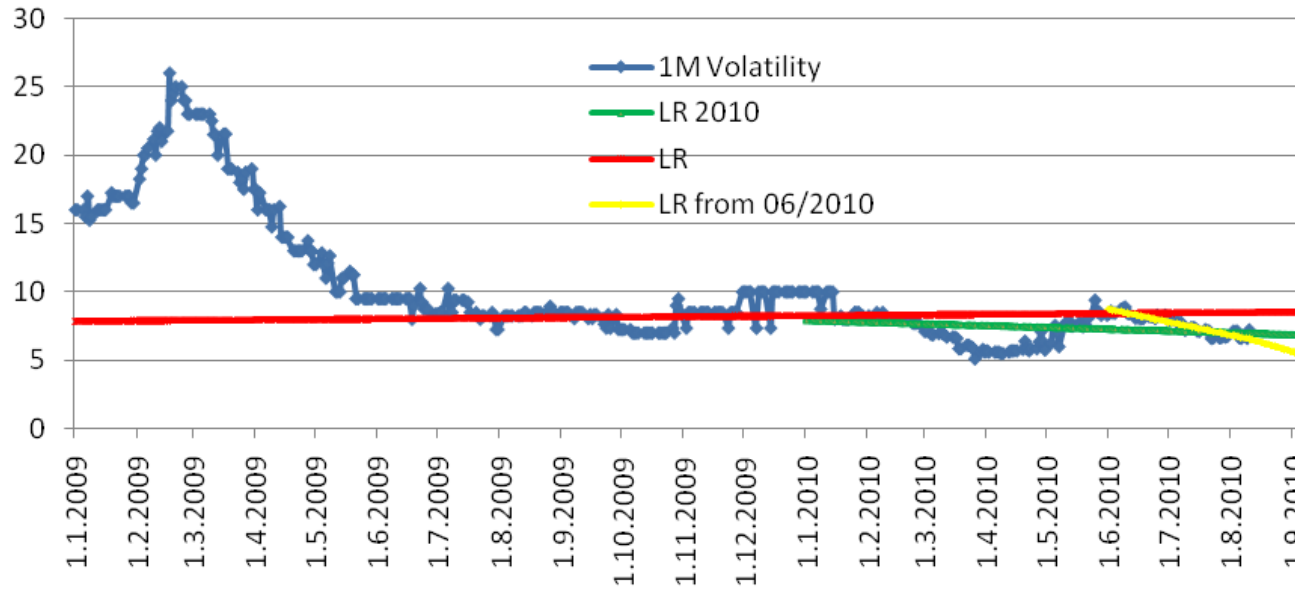

Source: Own calculations based on Thomson Reuters data

3: $1 M$ Volatility with LR predictions 
- Scenario LR2010

This scenario is based on a data model from 1.1 . 2010 until 10. 8. 2010 (historical data) and predicts the next month. As already seen in Fig. 2, the model is linear and therefore suitable for linear regression. The LR estimation confirms the decreasing trend of $1 \mathrm{M}$ volatility.

- Scenario LR from 06/2010

This scenario is based on a data model from 1. 6 . 2010 until 10. 8. 2010 (historical data) and predicts the next month. This data model is linear as well. The LR estimation confirms the decreasing trend of $1 \mathrm{M}$ volatility (stronger then LR2010).

\section{Interest rates}

In order to explore the whole currency pair of EUR/CZK, it is necessary to explore the PRIBOR
(Prague Interbank Offered Rate) and EURIBOR (Euro Interbank Offered Rate) rates as well.

The graph in Fig. 4 shows the decrease of interest rates for different time-periods (1M, 3M and 12M). Since the financial crisis begun, the CNB has reduced the REPO rate several times, which is reflected in PRIBOR rates. For the BIPS calculation it is necessary to explore the comparable EURIBOR rates as shown in Fig. 5.

There are a lot of similarities between the PRIBOR and EURIBOR. The financial crisis starts the period of reducing the REPO rates all around the world. Nevertheless, the starting point by EURIBOR was lower than the PRIBOR. The gap between the EUR and CZK interest rate remain but in the mean time is smaller.

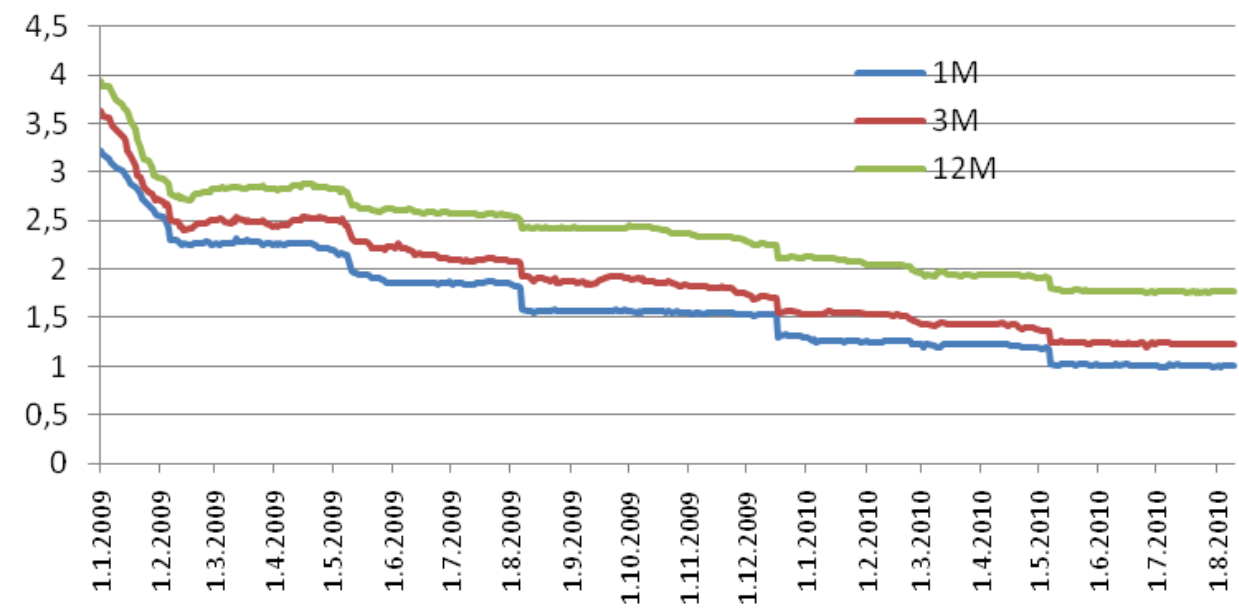

Source: Own graph based on Thomson Reuters (data provided by Komerční banka, a. s.)

4: PRIBOR for the time period 1.1.2009-10.8.2010

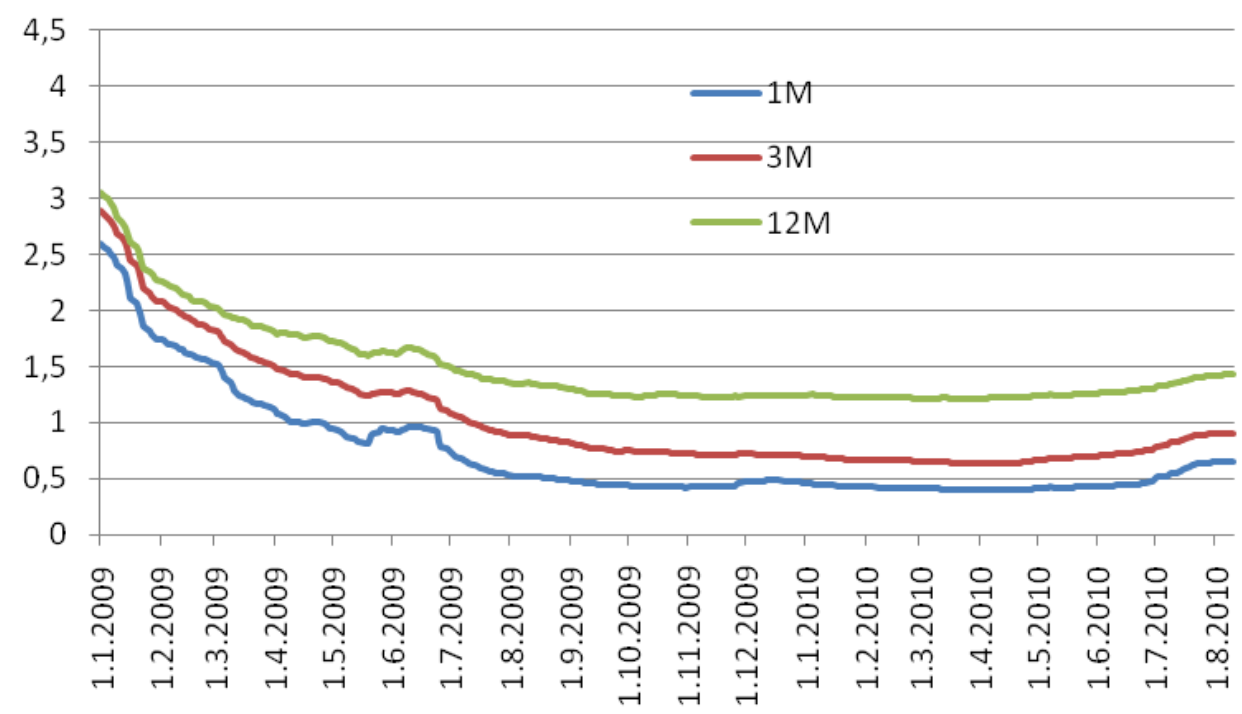

Source: Own graph based on Thomson Reuters (data provided by Komerční banka, a. s.)

5: EURIBOR for the time period 1.1.2009-10.8.2010 


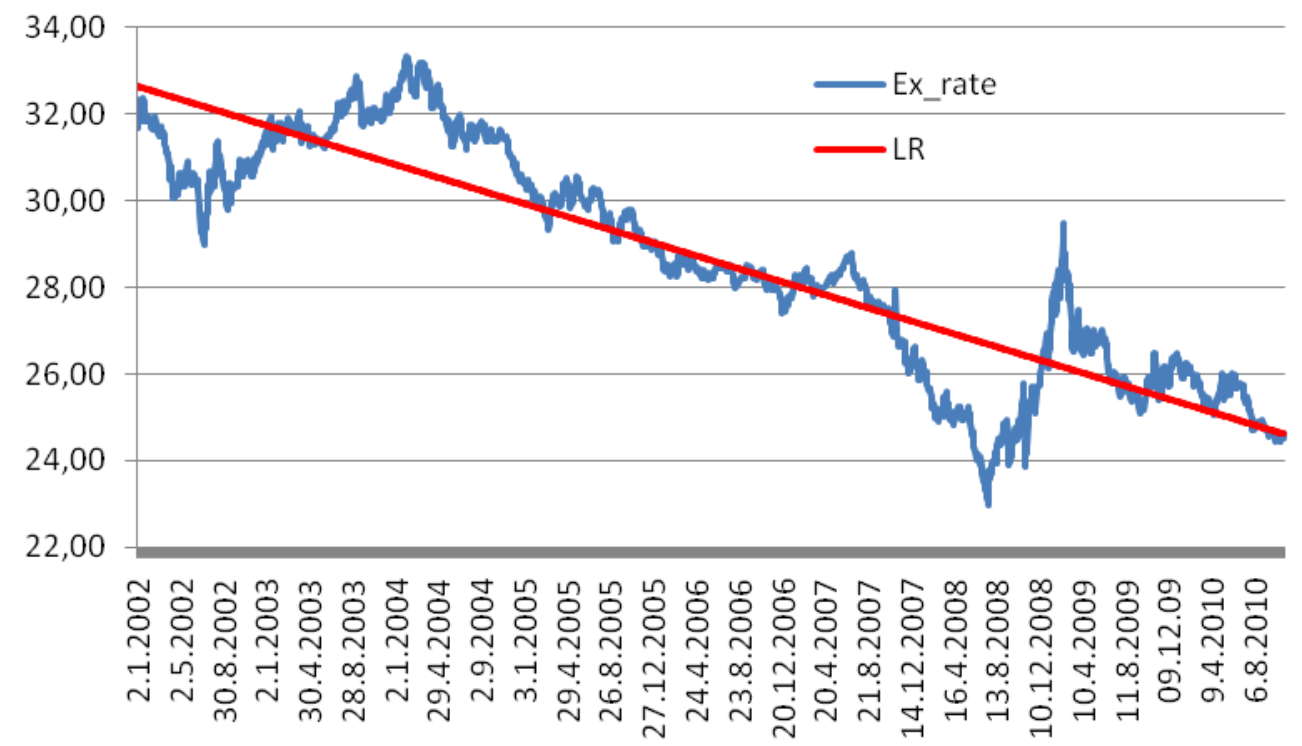

Source: CNB- fixing and own calculations

6: EUR/CZK for the time period 1.1.2002-26. 10.2010

\section{Exchange rate}

The main parameter for hedging strategy is the historical curve of exchange rate and future estimation of exchange rate development. The Fig. 6 shows the development of the currency pair EUR/CZK for the time period from 1. 1. 2002 until 26. 10.2010. The data set for the chosen time periods represents a linear data model suitable for linear regression analysis.

The curve based on linear regression computation shows strong trend of CZK-appreciation. The only significant fluctuations - from the long-term point of view - are the peaks (down and up) in the financial crisis. Only in this period of time was the $\sigma$ significantly higher, but still not high enough to change the trend.

\section{DISCUSSION}

From the long-term point of view, there is only an appreciation trend on the currency pair EUR/ CZK. Therefore the proper hedging strategy will be necessary for exporting companies, in order to minimize (or even better eliminate) the exchange rate risk.

Based on the interest rates analyses, there is still a gap between the PRIBOR and EURIBOR interest rates in favour of EURIBOR. This gap allows selling the EUR against the CZK in the future, for a better exchange rate as the traded SPOT.

And finally the volatility analysis and there shortterm prediction confirms the decreasing trend. Both significant scenarios for future volatility development (LR2010 and LR from 06/2010) are supporting the hypothesis of decreasing volatility.

Based on a.m. investigations, traditional hedging structures (Tab. I) and enhanced hedging structures (combinations of Tab. I, with KO, KI, windows or binary elements) can be used for the exchange rate hedging. The positive development of interest rates will allow to achieve better ATMF (at the money forward) strikes. The decreasing volatility will positively affect the option premium and makes the strategies more accessible.

\section{SUMMARY}

This paper deals with the exchange rate risk by the currency pair EUR/CZK from the Czech exporting company's point of view. Volatility (1M EUR/CZK), interest rates (PRIBOR and EURIBOR for selected periods) and exchange rates (EUR/CZK) have been analysed with help of linear regression. The real market data from Thomson Reuters are basement for prediction of future behaviour of volatility. Together with the confirmed trend of appreciation of CZK and positive interest rate differential, it creates a very solid basement for the hedging recommendation.

Based on these results, every exporting company providing the exchange rate risk management, should consider about making hedging operations. The current market situation offers good opportunities to make a suitable hedging. Advantages and disadvantages of selected structures are briefly mentioned. 


\section{REFERENCES}

ANDERSON, D. R. et al., 2007: Statistics for business and economics: Thomson Learning, ISBN 978-184480-313-2.

BOSSU, S., HENROTTE, P., 2006: Finance and Derivatives: John Wiley \& Sons, ISBN 978-0-47001432-5.

CHISHOLM, A. M., 2010: Derivatives demystified: a step-by-step guide to forwards, futures, swaps and options/ $2^{\text {nd }}$ edition: John Wiley \& Sons, ISBN 978-0-470-74937-1.

HENDERSON, C., 2002: Currency Strategy The Practitioner's Guide to Currency Investing, Hedging and Forecasting: John Wiley \& Sons. Ltd. ISBN 0-470-84684-4.
HUNT, P., J., KENNEDY, J., E., 2000: Financial derivatives in theory and practice: John Wiley \& Sons. Ltd. ISBN 0-471-96717-3.

KOLB, R., W., OVERDAHL, J., A., 2003: Financial derivatives, Third edition: John Wiley \& Sons, Inc. ISBN 0-471-23232-7.

THOMSONREUTERS, available from www. thomsonreuters.com.

WEISBERG, S., 2005: Applied linear regression $-3^{\text {rd }}$ ed.: John Wiley \& Sons, Inc. ISBN 0-471-66379-4.

YAN, X., GANG SU, X., 2009: Linear regression analysis: theory and computing: World Scientific Publishing Co. Pte. Ltd. ISBN-13: 978-981-283410-2.

\section{Address}

Ing. Sylvie Riederová, Ústav podnikové ekonomiky, Mendelova univerzita v Brně, Zemědělská 1, 61300 Brno, Česká republika 
